\title{
Sistema UAB: a visão dos coordenadores de polos de apoio presenciais da região sul
}

\author{
UAB system: the view of presence \\ support coordinators in the South region
}

Monica Pagel Eidelwein* Dilce Eclai de Vargas Gil Vicente** Maria Renata da Cruz Duran ${ }^{\star \star \star}$

\section{Resumo}

O sistema Universidade Aberta do Brasil (UAB) é composto pelo esforço das instituições de ensino superior, do governo federal (representado pela Coordenação de Aperfeiçoamento de Pessoal de Ensino Superior, Capes) e dos municípios e estados, que cumprem a função de criar e manter os chamados polos de apoio presencial. Num modelo de ensino a distância como o brasileiro, em que a modalidade é semipresencial, os polos de apoio presencial representam o locus desse tipo de formação docente. A partir da visão dos coordenadores de polos de apoio presenciais da região Sul, tentamos dar uma ideia do que seja esse sistema, qual sua contribuição e quais seus dilemas.

Palavras-chave: políticas públicas de formação de professores; sistema Universidade Aberta do Brasil (UAB); avaliação de polos UAB.

\section{Abstract}

The Brazil Open University system is composed by the efforts of institutions of higher education, the federal government (represented by the Coordination for the Improvement of Higher Education, Capes) and municipalities and states, which fulfill the function of creating and maintaining facility centers, which are called presence support poles. In a distance education model such as the Brazilian, in which the modality is semi-presencial, presence support poles represent the locus of this type of teacher education. According to the point of view of pole coordinators of South region, we tried to give an overview of this system, its contribution and dilemmas. Keywords: public policy for teacher training; Open University system in Brazil (UAB); evaluation of UAB poles.

\footnotetext{
${ }^{*}$ Coordenadora do Polo da Universidade Aberta em Novo Hamburgo (RS). monicapagel@yahoo. com.br

${ }^{* *}$ Coordenadora do Polo Universitário Santo Antônio (RS). dilcee@gmail.com

${ }_{* * \star}$ Professora adjunta de História Moderna e Contemporânea, Universidade Estadual de Londrina (www.uel.br).mariarenataduran@gmail.com
} 
Conforme dados do Censo de Ensino a Distância (EAD) 2013, realizado pela Associação Brasileira de Educação a Distância (Abed, 2013), 34,6\% dos cursos EAD autorizados em 2012 foram na área de ciências humanas. Destaque-se que essa também foi a segunda área de maior aumento na oferta de disciplinas EAD em cursos presenciais, totalizando 1.200 novas disciplinas cadastradas na modalidade. ${ }^{1} \mathrm{O}$ Censo ainda aponta o Ensino de Jovens e Adultos (EJA) como um dos principais nichos de desenvolvimento da EAD e mantém uma postura otimista em relação à expansão da modalidade no país. Segundo dados colhidos no site do sistema Universidade Aberta do Brasil (UAB) da Coordenação de Aperfeiçoamento de Pessoal de Nível Superior (Capes), atualmente, de um total de 104 instituições de ensino superior (IES) consorciadas, 17 universidades brasileiras ofertam o curso de graduação em história na modalidade $\mathrm{EAD}$, via sistema $\mathrm{UAB}$. Isso representa a abertura de cerca de 680 vagas anuais para estudantes de história nessa modalidade. É fato que os números não apontam nem uma ampliação galopante, nem uma maioria relativa da modalidade, ainda assim, o crescimento constante, a ampliação do número de disciplinas EAD nos cursos presenciais e a pressão social pelo reconhecimento da internet como um ambiente de aprendizado configuram algumas das principais justificativas para que o profissional da área de história dedique algo de sua atenção ao tema. Nesse ensejo, sugerimos focar essa atenção nas políticas públicas de indução e fomento da EAD, cuja dianteira é representada pelo sistema UAB.

O Sistema Universidade Aberta do Brasil (UAB) teve seu ato inaugural em dezembro de 2005, quando foi lançado um edital da Secretaria de Educação a Distância (SEED/MEC), em que se convidavam, de um lado, prefeituras municipais e governos de estado a oferecerem propostas para sediarem polos de apoio presencial e, de outro, instituições públicas de ensino superior a oferecerem propostas de cursos superiores na modalidade a distância. Na formulação do edital, estavam traçadas as principais linhas da cooperação federativa pretendida: os municípios e estados teriam como incumbência preparar e manter a infraestrutura de polos de apoio presencial, as IES ficariam responsáveis pela produção e execução dos cursos e pela matrícula dos estudantes e o MEC deveria custear integralmente o esforço acadêmico das instituições de ensino, inclusive com oferta de bolsas para professores e tutores. ${ }^{2}$ 
Num modelo de ensino a distância como o brasileiro, em que a modalidade é semipresencial, ou seja, os encontros presenciais são obrigatórios em cerca de 30\% da formação (avaliações e apresentações de curso/disciplina, além de estágios), os polos de apoio presencial representam o locus desse tipo de formação docente. Todavia, pouco se sabe acerca desse novo território educacional: quem trabalha nos polos de apoio presencial? Qual o organograma administrativo e como se ascende a ele? Qual o perfil do seu espaço físico? É uma escola, uma secretaria de educação ou um campus universitário avançado? Qual é o tipo de relacionamento que os formadores de formadores, no caso, as universidades, estabelecem com esses polos? Muitas são as questões que circundam esse espaço, que foi batizado por Fernando Haddad como "casa do professor", 3 e delas emerge o traçado da pesquisa ora apresentada.

A pesquisa que se apresenta neste artigo teve como mote a análise que os coordenadores de polos da região Sul fizeram de dois processos avaliativos pelos quais esses espaços passaram. ${ }^{4} \mathrm{O}$ primeiro ocorreu em 2010 e foi implementado pela Secretaria de Educação a Distância do Ministério da Educação (SEED/ MEC), e o segundo, em 2011, pela Diretoria de Educação a Distância (DED) da Capes (Costa; Duran, 2012, p.290-292). O resultado desses processos avaliativos, que suspenderam o funcionamento de cerca de $10 \%$ dos polos de apoio presencial e colocaram de sobreaviso cerca de $20 \%$ deles (foram emitidos pareceres com solicitações de melhorias e estabelecidos cronogramas de cumprimento dessas ações), serviu como estopim para um debate sobre os tipos de polos de apoio presencial existentes, suas demandas e carências (ibidem, p.290).

No âmbito desse debate, desenhamos nossa pesquisa com alguns vetores. Primeiro foi necessário estabelecer um recorte espaço-temporal. Estabelecemos os anos de 2006-2011, duração da primeira gestão da DED-Capes, liderada pelo professor Celso José da Costa, como nosso intervalo temporal. Nesse período, o sistema instaurou cerca de $90 \%$ dos polos e cursos hoje existentes. Depois, reconhecemos nas regiões Nordeste e Sul a maior proporção de polos por municípios do período, e na região Norte, a maior adequação aos objetivos estabelecidos pela legislação pertinente (capitalização e interiorização do ensino, conforme Decreto no $5.800 / \mathrm{MEC}){ }^{5}$

Estabelecido nosso recorte espaço-temporal, urgia traçar um perfil dos profissionais que atuam nesses espaços. Para isso, trabalhamos no desenvolvimento de pesquisas semiestruturadas acerca da formação docente e da trajetória 
profissional dos coordenadores de polos (Novoa, 1998). Num segundo momento, submetemos à análise daqueles coordenadores os instrumentos de avaliação SEED-MEC e DED-Capes via ambiente Moodle. Nessa dimensão de nossa investigação, a etnografia de Bueno (2007) e a netnografia de Mamede-Neves (2005) forneceram nosso suporte metodológico. Por fim, implementamos um processo que chamamos de "visitas cruzadas". Nelas, os coordenadores de polos de cada região se organizaram, de maneira eletiva, por pares. Cada dupla deveria simular uma visita avaliativa de maneira recíproca e, na sequência, postar, via Moodle, seu instrumento de avaliação preenchido para discussão, bem como um relatório sobre a experiência de estar no lugar do avaliador e do avaliado. Mais do que definir um perfil dos profissionais da área e de seu comportamento na rede (ambiente da EAD por excelência), essa etapa da pesquisa previa algum tipo de conscientização da ação e do processo avaliativo, tendo por base os pressupostos da pesquisa-ação (Miranda; Resende, 2006). Para mais, o resultado desse trabalho nos permitiu identificar como as avaliações oficiais vêm sendo realizadas no âmbito da EAD e quais são os seus efeitos nos municípios atendidos pela UAB.

\section{A formação docente na Região Sul e a CHEGAda da UAB}

A região Sul compreende os estados do Paraná, Santa Catarina e Rio Grande do Sul e é considerada a menor das cinco regiões brasileiras. Conforme o Censo de 2010 do Instituto Brasileiro de Geografia e Estatística (IBGE), sua população é de 27.384 .815 e ocupa a terceira posição populacional no país. Nos três estados, o ensino fundamental foi universalizado e o ensino médio está em processo de expansão.

Em 2001, ingressaram 1.043.308 estudantes no ensino superior no Brasil e, em 2010, o número de ingressantes passou a 2.182.229, de acordo com dados do Instituto Nacional de Estudos e Pesquisas Educacionais Anísio Teixeira (Inep). ${ }^{6}$ O Censo da Educação Superior de 2000 iniciou a coleta de dados sobre cursos a distância relatando a ocorrência de apenas três cursos na região, todos em instituições públicas, totalizando 3.110 ingressantes. Em 2010, foram ofertados 229 cursos em instituições públicas e privadas, com um total de 163.447 novos ingressantes. ${ }^{7}$ Destarte, o aumento de discentes na modalidade foi imenso, mas sua proporção em relação ao ensino presencial ainda é muito baixa. 
Não obstante, as universidades públicas deram prioridade para a formação docente em sua expansão no campo.

Atualmente, várias são as ações no sentido de incentivar a formação docente na região, a maioria delas direcionada à formação continuada e muitas na modalidade EAD. Em entrevista realizada por e-mail em fevereiro de 2012, Silvio Rocha, diretor pedagógico da Secretaria de Educação do Estado do Rio Grande do Sul, destacou, entre as ações: a) o programa Novo Ensino Médio (Departamento Pedagógico - SEDUC - 2011), necessário devido à reestruturação curricular desse nível de ensino; b) o programa Formação sobre Progressão Continuada na Alfabetização e Letramento dos Alunos do $1^{\circ}$ ao $3^{\circ}$ anos do Ensino Fundamental, direcionado a todos os setores da educação básica e envolvendo professores dos 3 primeiros anos do ensino fundamental, coordenadores pedagógicos e gestores, e c) as parcerias com universidades, buscando a formação inicial para professores da Rede Estadual de Educação, com o objetivo de formar em 4 anos 100\% desses profissionais em licenciaturas.

No estado de Santa Catarina também podem ser destacadas várias ações relativas às políticas públicas de formação dos professores, de acordo com informações fornecidas pela Secretaria Estadual de Educação:

para facilitar o planejamento estratégico para a oferta de cursos de formação inicial e continuada criamos, e ainda está em fase experimental, o programa SC Formação. É um sistema de gestão da formação inicial e continuada da rede pública de ensino de Santa Catarina. O sistema objetiva facilitar o diagnóstico das demandas de formação inicial e continuada dos profissionais da educação da rede pública de ensino de Santa Catarina. ${ }^{8}$

No estado do Paraná, uma atualização dos programas da Secretaria Estadual de Educação (SEED) está em curso; todavia, ainda não foram publicados dados pertinentes, mesmo que se saiba da continuidade do Programa de Desenvolvimento Educacional (PDE), que desenvolve boa parte de suas atividades via Moodle.

Muitas ações também foram implementadas pelos municípios da região. ${ }^{9}$ Nesse quadro, o sistema UAB, que conta com a adesão de 14 IES da região Sul (13 até 2011), reforçou a política regional contribuindo para uma maior capilarização da formação docente em nível universitário. A Tabela 1 mostra dados de interiorização do ensino superior na região Sul, através do sistema da UAB: 
Tabela 1 - Número de municípios e de Polos de Apoio Presencial da Universidade Aberta do Brasil na Região Sul

\begin{tabular}{c|c|c|c}
\hline Estado & Município & Polos UAB & \% Polos/Brasil \\
\hline Rio Grande do Sul & 496 & 39 ativos & 7,87 \\
Santa Catarina & 293 & 36 ativos & 12,29 \\
Paraná & 399 & 47 ativos & 11,78 \\
\hline
\end{tabular}

Fonte: IBGE Censo 2010. Disponível em: http://www.ibge.gov.br/estadosat/perfil. php?sigla=rs; e SisUAB. Disponível em: http://uab.capes.gov.br/sisuab/ConsultaPolos.action; Acessos em: 10 jan. 2012.

É nos cursos de licenciatura que está o maior número de matrículas da EAD na região Sul, com cerca de $48 \%$ das matrículas, de acordo com o Censo da Educação Superior (2010). Não obstante, dos 17 cursos de graduação em história do sistema, cinco estão na região - atrás, apenas, da região Nordeste, onde estão alojados oito cursos de graduação em história nessa modalidade, conforme os dados do site oficial da UAB-Capes. Outra das especificidades da modalidade a distância na região Sul é que, embora a região Sudeste ofertasse, em 2010, um maior número de cursos, totalizando 391 nessa modalidade (seguida pela região Sul, com 229 cursos), foi no Sul que ocorreu a maior quantidade de matrículas na modalidade, com 397.891 matriculados em 2010, ultrapassando a região Sudeste, com 297.273 matriculados (Censo Educação Superior, 2010). Nesse sentido, caso a proporção se mantenha, é possível inferir que um número considerável de historiadores da região seja formado na modalidade EAD.

Aliás, qual é o perfil do estudante dessa modalidade? Na região Sul, quanto à idade dos alunos, nos cursos presenciais, a média é de 26 anos e, nos cursos a distância, 33 anos. Esses dados mostram que os cursos a distância atendem a um público com idade mais avançada, possibilitando inferir que a opção pela modalidade a distância proporciona o acesso à educação superior para aqueles que não tiveram oportunidade de ingressar na idade adequada nesse nível de ensino, ou ainda, para aqueles que já estão no mercado de trabalho. Além disso, a EAD atende, sobretudo, a professores ou aspirantes à carreira docente. Assim, outro dado a destacar diz respeito ao perfil do professor da região. O estudo exploratório sobre o professor brasileiro com base nos resultados do Censo Escolar da Educação Básica de $2007^{10}$ aponta para um grupo de professores cuja 
maioria é do sexo feminino, na faixa etária de 40 anos, atuando prioritariamente em uma única escola da rede urbana municipal. Este, conforme nossas investigações, é também o quadro que configura a demanda do sistema UAB.

Vale dizer que, segundo o mesmo estudo (Inep, 2009), a principal carência na formação de professores da região Sul está situada nas áreas de artes e das ciências naturais, como física e química. Comparando-se os dados do Censo do Professor ${ }^{11}$ com as ofertas de curso UAB, obteremos a Tabela 2:

Tabela 2 - Comparativo entre as demandas do Censo e a oferta UAB

\begin{tabular}{c|c|c|c|c}
\hline \multirow{2}{*}{$\begin{array}{c}\text { Demanda } \\
\text { do Censo }\end{array}$} & \multicolumn{4}{|c}{ Oferta pelo Sistema UAB } \\
\cline { 2 - 5 } & Estado & Instituição & $\begin{array}{c}\text { Curso } \\
\text { ofertado }\end{array}$ & $\begin{array}{c}\text { Polos que } \\
\text { ofertam o curso }\end{array}$ \\
\hline Artes/RS & PR & Unicentro & Artes & 5 \\
Física/PR & PR & UEM & Física & 6 \\
Física/SC & SC & UFSC & Física & 8 \\
Física/RS & RS & UFSM & Física & 8 \\
Química/RS/SC/PR & 0 & 0 & Química & 0 \\
\hline
\end{tabular}

Fonte: dados do SisUAB disponíveis em http://uab.capes.gov.br/sisuab/ConsultaArticulacoes.action; Acesso em: 24 jan. 2012. Na primeira linha da tabela, estão corretas as notações "RS" e "PR"; há mesmo uma incongruência entre a demanda do Censo do Professor e a oferta pelo sistema UAB.

O que se pode notar, portanto, é que, embora se procure provocar um diálogo entre universidades e mantenedores de polos, isto é, municípios e estados, sobre a oferta de cursos mais coerentes com as necessidades regionais, nem sempre isso acontece.

Isso também nos leva a refletir sobre outro ponto: qual a contribuição de projetos como o sistema UAB em regiões como a que estamos estudando? Ora, a região Sul já possui políticas públicas estaduais e municipais para seus docentes, muitas delas em parceria com as IES locais, entretanto, nem sempre essa formação ocorre mediante uma relação sólida entre governos e IES. Em alguns casos, as IES apresentam programas alternativos para a formação docente, que nem sempre fazem parte de um projeto nacional, e, por isso, são distintos de um padrão tradicional, sendo, algumas vezes, considerados como limitados ou inferiores do ponto de vista da qualidade. 
A volatilidade dos programas estaduais e municipais é outro empecilho para a qualidade da oferta. Como a universidade é um ambiente de decisões colegiadas, a absorção de projetos e programas externos ou em regime de parceria é lenta. Essa falta de sincronia entre os tempos da universidade e das políticas públicas de formação docente impede, do ponto de vista da universidade, que tais projetos sejam integrados ao organograma interno conforme o princípio do mérito e da qualidade que rege essas instituições. Internamente, as universidades passam a atender a tais demandas com os recursos humanos de discentes de pós-graduação, docentes em início ou fim de carreira, enfim, sem a presença daquele que seria considerado seu time de primeira linha (que opta por investir em programas de longo prazo, em que sua carreira profissional possa se fortalecer).

Com a UAB e, pouco a pouco, sua institucionalização, configurada, entre outros, pelo reconhecimento da carga horária docente nesse campo, a formação docente passa a ser considerada como uma linha permanente de atuação dentro das universidades, e isso nos leva a crer numa melhoria gradual da qualidade da oferta, uma vez que a UAB passa a constituir um chamariz para pesquisadores e professores de peso nas universidades.

Para a efetivação desse sistema faz-se necessária, portanto, a organização das IES para a oferta de cursos na modalidade a distância e a criação, bem como a qualificação, de polos de apoio presencial com coordenadores e tutores presenciais. A fim de refletir sobre a melhor qualificação desses polos passamos a um estudo acurado do perfil do coordenador de polo da região Sul e suas demandas.

\section{O COORDENADOR DE POLO DA REGIÃo SUl E SUAS DEMANDAS}

Ao entrevistar os coordenadores de polos $\mathrm{UAB}$ da região Sul, encontramos professoras, em sua maioria na faixa de 40 anos, e com alguma experiência na área de gestão escolar. ${ }^{12}$ Elas foram escolhidas para trabalhar nos polos pela equipe DED-Capes com base na indicação dos mantenedores (que podem ser prefeituras municipais e governos estaduais) através de lista tríplice, para implantar e coordenar polos de apoio presencial. $\mathrm{Na}$ entrevista semiestruturada, os coordenadores da região Sul revelaram sua opinião sobre a importância da $\mathrm{UAB}$ em cada município sede e na região de abrangência dos seus polos, 
principalmente no acesso ao ensino superior. Muitos depoimentos de alunos foram rememorados de forma emocionada:

Sábado eu tive uma aula inaugural com 91 alunos do curso de pedagogia e, olhando para plateia, vi pelo menos oito mulheres que fizeram o magistério comigo e só agora vieram fazer o curso de pedagogia. Quanto tempo já passou, quantas pessoas foram excluídas do processo... Tenho um aluno de matemática que mora a $40 \mathrm{~km}$, na zona rural. Esse menino, para falar no celular, precisa subir em uma árvore, pois é o único ponto que dá acesso ao sinal. Para realizar as tarefas, ele anda $8 \mathrm{~km}$ e vai até uma escola que tem computadores, além de ir ao polo todas as terças e quintas. Esse aluno, no segundo ano do curso, já passou no concurso do IBGE. Hoje, outros como ele, vindos do interior, do sítio, foram contratados pelo estado do Paraná e estão trabalhando. (coordenadora polo Ibaiti, PR, 2011) $)^{13}$

Assim, o que se pode notar é uma relação afetiva de muitos coordenadores de polos com a atividade realizada no âmbito do sistema, o que, entre outras coisas, denota seu comprometimento com tal tarefa. Nas entrevistas, os coordenadores da região Sul também se revelaram professores com experiência em gestão da educação, lideranças atuantes em projetos educacionais inovadores e na formação de professores municipais e estaduais, características que foram decisivas para a indicação desses profissionais para a função de coordenadores de polos. Poucos, porém, possuíam experiência e conhecimento em educação a distância.

Na gestão diária dos polos, foram destacadas dificuldades como: falta de acesso ao Moodle dos cursos de algumas instituições; falta de autonomia para organizar a equipe de trabalho (muitos coordenadores, sem contar com a colaboração de funcionários de apoio, tentam dar conta de toda a demanda de trabalho); dificuldade em lidar com as orientações diferentes de cada instituição no que se refere à atuação e ao cumprimento de carga horária dos tutores (as instituições não estão acostumadas a trabalhar em conjunto) e dificuldades com a falta de orçamento direto para o polo.

Avanços foram percebidos, como a organização da documentação legal pelos polos (Lei de Criação dos Polos, Regimento Interno e Plano de Gestão) e a conquista de recursos para sua manutenção, como mencionado neste depoimento: 
Nosso polo tem os documentos legais com todas as obrigações do mantenedor... Ganhei um fundo de gestão para pequenas despesas do polo, como as escolas têm. (coordenadora polo Pato Branco, PR, 2011)

Quanto à formação dos coordenadores de polo, 73\% possuem pós-graduação lato sensu e formação específica em educação. A titulação desses coordenadores dos polos aponta para a importância do investimento realizado na formação continuada, especialmente em educação a distância, o que nos faz valorizar iniciativas como a da Universidade Federal de Pelotas (RS), que ofertou a Especialização em Gestão de Polos para os coordenadores da região Sul, no sistema UAB.

Os coordenadores de polo reclamam da falta de formação continuada em educação a distância, mas já afirmam trazer uma bagagem em gestão da educação. Muitos deles destacam que a participação nos eventos realizados nos polos é de grande valia para essa formação, assim como as reuniões do Fórum Nacional de Coordenadores UAB e a manutenção do Ambiente de Trabalho UAB, o Atuab, da Diretoria de Educação a Distância da Capes. ${ }^{14}$

No que tange às atribuições do coordenador do polo, encontram-se entre as principais: acompanhar e coordenar as atividades docentes, discentes e administrativas do polo; garantir às atividades da $\mathrm{UAB}$ a prioridade de uso da infraestrutura do polo; acompanhar as atividades de ensino, presenciais e a distância; zelar pela infraestrutura do polo; articular, com as Instituições Públicas de Ensino Superior (Ipes), a distribuição e o uso das instalações do polo para a realização das atividades dos diversos cursos; organizar, com as Ipes, calendário acadêmico e administrativo que regulamente as atividades dos alunos naquelas instalações; articular-se com o mantenedor com o objetivo de prover as necessidades materiais, de pessoal e de ampliação do polo, e receber e prestar informações aos avaliadores externos do MEC.

Para os coordenadores, a gestão de um polo passa pelo domínio de um rol de conhecimentos que fazem parte de um cenário novo para o educador brasileiro. É fundamental afinar os conhecimentos e criar mecanismos capazes de propiciar o planejamento, a organização e a capacitação da direção e do controle das atividades desenvolvidas. De acordo com Silva et al. (2010), os coordenadores dos Polos de Apoio Presencial da UAB devem receber formação para atuar na gestão do polo em diferentes dimensões - gestão estratégica, 
gestão de projetos, gestão de infraestrutura, gestão de equipe e gestão de processos -, visando alcançar uma uniformidade de ações e resultados.

O papel do coordenador, nesse paradigma de gestão, é articular a participação, criar oportunidades de aprendizagem, promover as ideias e projetos e inserir o polo no contexto do campo e da cidade. Quando os coordenadores foram questionados, na entrevista, sobre características indispensáveis à função, afirmaram que experiência docente e em gestão da educação e conhecimentos em educação a distância e em informática são fundamentais.

Segundo eles, se o polo fosse apenas um local para a realização de momentos presenciais de um curso que só acontece no ambiente virtual, bastariam uma sala de aula, banheiro limpo e alguém para abri-lo e fechá-lo. Mas, quando se entende que o curso acontece no ambiente virtual e no polo, este passa a ser um local de encontro permanente e os tutores presenciais e o coordenador do polo são responsáveis, com as IES, pela articulação dos estudantes e pelo sucesso do curso. Nessa perspectiva, o coordenador de polo deve ser alguém que entenda a modalidade de ensino, com experiência em gestão da educação e conhecimentos de Tecnologias da Informação e da Comunicação (TICs) aplicadas à educação, e que faça do polo não somente um ambiente físico, mas um ambiente pedagógico. A partir da análise das entrevistas, percebemos que, apesar de os coordenadores compreenderem a necessidade de todos esses conhecimentos, muitos ainda não correspondem ao perfil defendido.

\section{Avaliação DE POLOS}

A implantação dos polos UAB foi acompanhada por avaliações realizadas pelas IES, pela SEED-MEC, pela DED-Capes e pelo Inep..$^{15}$ De todas elas, a avaliação realizada pela SEED-MEC, em 2010, foi a mais polêmica, como se observa neste testemunho:

O polo de Santo Antônio da Patrulha foi avaliado com nota máxima, porém registros equivocados prejudicaram o polo, como, por exemplo, dizer que a biblioteca funciona junto com a secretaria, sendo que a avaliadora visitou a biblioteca em ambiente específico, organizada e até com consulta online sobre a disponibilidade de materiais. O prejuízo para o polo veio logo, pois a ausência de ambien- 
te específico bloqueia o cadastro de novos cursos. (coordenadora Polo Santo Antônio da Patrulha, RS, 2012)

Participaram de nossa pesquisa cinco coordenadores de polos do Rio Grande do Sul, sete coordenadores de polos de Santa Catarina e dez coordenadores de polos do Paraná, totalizando 22 polos, cujos coordenadores realizaram visitas cruzadas de avaliação e uma reflexão sobre o instrumento de avaliação. Os 22 polos atendem 10.647 alunos; 18 são mantidos pelas prefeituras municipais e dois, pelos estados; dois não informaram quais eram os mantenedores. ${ }^{16}$

Os cursos ofertados nesses polos priorizam a formação inicial e continuada de professores, e aproximadamente $50 \%$ desses municípios utilizam a internet do programa Banda Larga na Escola somada a um link mantido pelas prefeituras. Percebe-se, ainda, que os recursos de informática estão atendidos na maioria dos polos, porém, há outros com falta de equipamentos em quantidade adequada ao número de estudantes.

Quanto à infraestrutura (espaço físico, internet e horário de funcionamento), muitos polos foram avaliados como satisfatórios. Todavia, a avaliação mostrou que, apesar de a maioria das bibliotecas estar organizada, em funcionamento e com acervo básico adequado, as instalações poderiam ser melhoradas. Além de uma análise dos laboratórios de informática e de áreas específicas, como física e química, esse aspecto constituiu a parte mais importante, ou de maior valor (em termos de nota final) do processo avaliativo oficial. Em segundo lugar, figurou a existência e a carga horária dos recursos humanos do polo, sem, no entanto, haver, no questionário que orientava a avaliação, itens relativos à ocupação pedagógica desses funcionários.

Os coordenadores de polos apontaram pontos críticos da avaliação, durante a pesquisa. Segundo eles, a avaliação não contemplou características específicas da região, dos cursos ofertados, da agenda cultural e pedagógica local e da ciberinfraestrutura que porventura os polos tenham desenvolvido. Para alguns, a aplicação ou o empenho pedagógico nos polos não mereceram a atenção devida. Nesse caso os coordenadores de polos foram entendidos como zeladores de prédios, sendo desconsiderados os usos pedagógicos desses espaços; segundo eles, o polo representa, sim, o locus da formação universitária docente. 
Infelizmente, não pudemos comparar as notas conferidas mutuamente pelos coordenadores de polos com as notas das avaliações oficiais, porque muitos polos ficaram sem nota final na nossa pesquisa-ação. Isso mostra a dificuldade do avaliador em sintetizar a avaliação e atribuir uma nota, mas também pode ser explicado pelo possível constrangimento dos coordenadores em atribuir notas aos colegas de trabalho. Apesar disso, a questão mais importante foi o entendimento do significado da avaliação por parte desses coordenadores. Para eles, ela não deve se limitar a observar a infraestrutura e o funcionamento do polo. Ao contrário, avaliar o polo significa olhar para as diferentes dimensões que são necessárias na formação através da educação a distância. Isso significa contemplar, além da infraestrutura, a interação, o papel dos diferentes atores envolvidos (tutor, professor, aluno, coordenador de curso, coordenador de polo), as tecnologias e a proposta pedagógica do curso. "A avaliação não se reduz a contar cadeiras e medir salas; é necessário considerar o que acontece dentro dessas salas", (coordenadora do polo de Novo Hamburgo, RS, 2012). Por conseguinte, nos pareceu imprescindível problematizar esta temática.

\section{UMA NETNOGRAFIA ${ }^{17}$ NA MODALIDADE EAD}

Para aprofundar as reflexões sobre as avaliações oficiais analisamos também os fóruns de discussão do ambiente Moodle criados especialmente para esta pesquisa pelo Laboratório de Novas Tecnologias Educacionais da Universidade Federal Fluminense (Lante-UFF). Nesse ambiente, os coordenadores de polos da região Sul destacaram que a avaliação tem sido entendida, em muitas situações, apenas como um meio pelo qual são constatadas as deficiências e, por isso, acaba sendo utilizada para "rankeamento" do polo e não como um meio para a qualificação do trabalho que ali é realizado. De acordo com o coordenador do polo de Criciúma (SC), "o avaliador deve ter o conhecimento do porquê de estar avaliando, qual a finalidade da avaliação, e não com um tom ameaçador ou até punitivo ao polo". Nesse mesmo sentido, o coordenador do polo de Sapiranga (RS) escreveu que "a avaliação deve ser algo periódico e que aponte, sobretudo, caminhos a se percorrer”. Além disso, os coordenadores apontaram que nem sempre os critérios da avaliação são claros e conhecidos previamente. Como afirmou a coordenadora do polo de Chapecó (SC), em 2012, "o instrumento de avaliação de polos deve ser sucinto, objetivo e 
claro, com questões dentro dos pré-requisitos propostos para a implantação de polos pelo MEC-Capes".

Segundo os coordenadores, a falta de um consenso - entre os avaliadores - sobre o que é um polo de apoio presencial leva a equívocos na avaliação. Muitos avaliadores acabam entendendo o polo como o local responsável apenas por executar as demandas das universidades e dos mantenedores, reforçando, assim, uma hierarquização das funções e desconsiderando que o polo é também um local de produção de saberes. Se não se tem a dimensão do que ocorre nesse espaço, os atores nele envolvidos acabam se tornando invisíveis, havendo um silenciamento de suas vozes. De acordo com uma das coordenadoras do polo "o conhecimento que o avaliador tem da realidade da EAD e do sistema UAB é fundamental para que se faça uma análise do polo de forma mais justa" (coordenadora do polo de Santa Vitória do Palmar, RS, 2012). Nesse sentido, houve recomendações de que o avaliador tivesse conhecimento de avaliações que o próprio polo costuma fazer:

Penso que uma avaliação deva vir de dentro para fora; temos plenas condições de avaliar o polo, somos parte fundamental, queremos o melhor para o nosso polo. Se ele não está bem e precisa melhorar, seremos os primeiros a apontar isso! (coordenador do polo Sapiranga, RS, 2012)

Além disso, em algumas situações, a avaliação do polo é desvinculada da avaliação dos diversos segmentos que o compõem e, por isso, não abrange a complexidade do sistema como um todo. Nesse sentido, uma das coordenadoras sugeriu:

O avaliador deveria receber no mínimo o histórico do município em que está inserido o polo, suas deficiências, pontos fortes e fracos, no que tange a infraestrutura, o envolvimento das IES, do mantenedor, para que não fique somente uma avaliação superficial para preencher mero procedimento burocrático. (coordenadora do polo Araranguá, SC, 2012)

A complexidade desse sistema também é enfocada nesta fala:

O ideal seria o avaliador conhecer a história do polo, o mantenedor do município, a clientela, o trabalho e a contribuição dos coordenadores, tutores e a importância que estes têm para os alunos que frequentam cursos na modalidade 
EAD, pois esse espaço é considerado como "braço" de apoio das IES. (coordenadora do polo Astorga, PR, 2012)

Foram lembrados casos de desarticulação da avaliação. Por exemplo, quando alguns coordenadores foram questionados sobre a existência de laboratórios de física ou química, mesmo não havendo cursos nessas áreas, o polo foi avaliado como insuficiente nesse quesito, por não possuir determinados laboratórios. Em outros casos, mesmo havendo o curso, mas, tendo a IES ofertante entendido que esse espaço não seria necessário, pois o projeto pedagógico não previa a sua utilização, e sim simulações realizadas no ambiente virtual, o polo também foi avaliado de maneira insatisfatória. Noutros polos ainda se destacou a utilização de espaços da comunidade ou da universidade em momentos pontuais, de aulas práticas, inclusive avaliando como positiva a experiência da ida dos alunos esporadicamente à IES (com vistas à integração ao ambiente acadêmico) ou às escolas locais (com vistas à aproximação do ambiente profissional), mas, também nesses casos, as avaliações oficiais foram negativas. ${ }^{18}$ Para os coordenadores,

O fato é que fomos altamente prejudicados em itens que constavam no formulário e que não tínhamos... Tipo: conceito 1 (precário) em biblioteca, laboratórios, sobretudo de biologia, química... Nem possuímos esses cursos! É complicado! (coordenador do polo Sapiranga, RS, 2012)

Desse modo, entende-se que a exigência de espaços deve estar em acordo com o número de instituições, de cursos ofertados e de alunos e ainda de acordo com o projeto pedagógico dos cursos. Para os coordenadores, deve-se discutir, antes da oferta dos cursos, as necessidades estruturais, de acordo com a proposta, para a modalidade a distância, analisando-se as reais possibilidades de o mantenedor garantir aquela infraestrutura. Como alguns coordenadores assinalam, nem sempre os municípios têm condições de despender cerca de 200 mil reais em um laboratório de química, por exemplo. Assim, critica-se a ideia de uma determinação prévia de espaços desvinculada das reais possibilidades e necessidades apresentadas e destaca-se a importância de instrumentos e de parâmetros de avaliação flexíveis, o que não significa a inexistência deles, apenas uma maior capacidade de diálogo das partes envolvidas na formação docente. Todas essas críticas corroboram a impressão de que a articulação 
polos + IES + governo federal é desigual e de que, no jogo das políticas públicas combinadas, todos ainda têm muito a aprender.

Segundo os coordenadores, para que a avaliação de polos possa contribuir com a qualificação desses espaços, é necessária uma reflexão também por parte dos outros envolvidos nessa parceria. Quando um polo tem sua nota reduzida, a responsabilidade, de um lado, também é das IES, que nem sempre atuam de maneira integrada, informativa e/ou democrática com os polos, e, de outro, do governo federal, que muitas vezes multiplica regras gerais sem atentar para a realidade local ou mesmo para a contradição de algumas de suas recomendações. Nesse sentido, a presença de um representante do mantenedor do polo e também da universidade no momento da avaliação é fundamental, pois, quando se avalia o polo, necessariamente se avaliam os segmentos que o compõem.

Quanto à atuação do profissional que realiza a avaliação do polo, os coordenadores salientaram que nem sempre ele está preparado para realizar essa atividade, tendo uma postura inadequada. Constataram algumas práticas que prejudicam a avaliação e que indicam a necessidade de um investimento na formação desse profissional. Mencionaram que algumas vezes o avaliador não comunica com antecedência a sua vinda ao polo e não se apresenta formalmente. Além disso, o pouco tempo de permanência no polo e o relatório muito extenso fazem que o avaliador se ocupe majoritariamente da formalidade do preenchimento do documento e tenha uma visão muito restrita, de aspectos pontuais, ocasionando, em alguns casos, generalizações por vezes equivocadas e uma visão parcial. Muitas vezes o avaliador desconhece as especificidades do polo dentro da perspectiva da UAB e não conhece a educação a distância, utilizando a educação presencial como referência. Finalmente, ainda de acordo com os coordenadores, cada avaliador interpreta de maneira diferente as questões do instrumento de avaliação, ficando o resultado da avaliação vinculado à subjetividade de cada avaliador.

A pesquisa apontou, portanto, a necessidade de o avaliador emancipar-se do modelo de espaço da própria universidade, seja de cursos presenciais ou a distância, para pensar os polos como espaços peculiares, que ofertam cursos com características diferenciadas, de diversas universidades, e cujos mantenedores são estados ou municípios, também com condições diferenciadas. 
Nesse sentido, para os coordenadores, discutir a avaliação dos polos torna-se pauta urgente para a educação, quando se pensa em qualificá-la. Primeiro, por haver pouca produção acadêmico-científica que trate desse tema; depois, pela urgência de qualificar a própria avaliação para que sirva de indicador de direção para os polos, possibilitando, com isso, consolidar a oferta de cursos com maior qualidade. Por essas razões, a proposta de um mestrado direcionado para tal público é cabível e necessária. Não apenas porque muitos coordenadores de polos padecem da falta de conhecimentos amplos sobre a universidade, seu funcionamento e importância, mas também porque tanto os polos como as IES seriam incitados a produzir conhecimentos sobre o assunto.

\section{CONSIDERAÇÕES FINAIS}

No artigo ora apresentado foi exposta uma pesquisa sobre o sistema UAB. Política pública de formação docente na modalidade de ensino a distância, o sistema UAB articulava, em 2011, esforços de 92 instituições públicas de ensino superior, do governo federal (Capes) e de cerca de seiscentas mantenedores de polos de apoio presenciais, que, representados por governos municipais e estaduais, se dispõem a criar e manter espaços de formação para docentes de ensino básico e médio da rede pública de instrução. No recorte ora apresentado, foram reunidos alguns dos principais indicadores do perfil dos coordenadores de polos da região Sul, da gestão implementada nesses espaços e da maneira como eles veem a avaliação de seu trabalho. Espera-se, com a revisão aqui exposta, ter fornecido um panorama geral do que seja o sistema UAB, sua complexidade, implicações, limites e potenciais. Bem como dos polos de apoio presenciais, que, em nossa mirada, constituem uma das singularidades da EAD latino-americana. Destaque-se que não há pares dos mesmos em sistemas como os da Open University, no Reino Unido, ou da Universidad Nacional de Educación a Distancia (Uned), na Espanha, grandes baluartes da EAD mundial, embora haja Centros Zonais no projeto Enlaces do Chile. Essa singularidade, obviamente, tem como pano de fundo nossas dificuldades tanto de conexão em rede quanto de inclusão digital de nossa população e, por fim, mas não menos importante, as limitações financeiras de nossos docentes ao acesso de equipamentos que envolvam a tecnologia. 
Todas essas dificuldades, entretanto, têm se amainado nos últimos 10 anos, como se pode notar nas pesquisas do CETIC.Br (TIC Educação 2013), e o acesso à internet entre a população escolar chega a alcançar um patamar de 94\% de usuários, cada vez mais via dispositivos móveis. Nesse cenário, a internet não se configura apenas como uma ferramenta de instrução democrática e passível de uso massivo, mas também como um elemento instrucional que ultrapassou os muros do laboratório de informática e que, assim como os livros, precisa estar presente, de maneira orientada, em sala de aula. Com os dispositivos em mãos, os futuros professores de história devem ter em mente que um de seus maiores desafios é resistir à flanerie virtual quando se trata de estudar na rede. Para isso, é imprescindível que os formadores de formadores (nesse caso, professores universitários, e eis um dos ganhos da UAB) saibam conduzir essa leitura que, diferente da leitura de um livro, é aberta, fragmentada e sensorial, ou seja, o docente deve indicar as direções, mas o caminho é do discente, que precisa aprender a aprender nesse ambiente. Das universidades, essa orientação é feita diretamente via computadores; dos polos, essa ação é presencial e, muitas vezes, ainda representa o esteio de segurança que esse discente, sempre atemorizado pela tecnologia dos filmes de ficção científica (que em filmes como 2001, uma odisseia no espaço, chegam a atentar contra a vida humana), terá para efetivar seu processo de inclusão digital. Para mais, espera-se ter destacado, no modelo compartilhado de poder do sistema UAB, a emergência de um novo paradigma de formação docente, em que as universidades vão até comunidades distantes e atuam, sistematicamente, em parceria com forças municipais, estaduais e federais, o que nos garante, se não a confirmação de antigas competências, a renovação desses laços, bem como a retroalimentação do sistema universitário, seja no que diz respeito ao modo como a universidade é vista pela sociedade (mais próxima, mais móvel, mais inclusiva, mais dinâmica), seja no que diz respeito ao modo como a universidade se constrói internamente (diversificando seu público e suas modalidades de atendimento).

\section{REFERENNCIAS}

ABED. Censo EAD.BR: Relatório Analítico da Aprendizagem a Distância no Brasil. 2012. Analytic Report of Distance Learning in Brazil/ [traduzido por Opportunity 
Translations]. Curitiba: Ibpex, 2013. Disponível em: http://www.abed.org.br/site/ $\mathrm{pt} / \mathrm{midiateca} /$ censo_ead/.

AMIEL, T.; DURAN, M. R. C.; COSTA. C. Investigating the estruture of the Open University of Brazil. In: EDEN, 2014, Zagreb, Croácia, Polycom, 2014.

BRASIL. Decreto no 5.800, de 8 de junho de 2006. Dispõe sobre o Sistema Universidade Aberta do Brasil - UAB.

BRASIL. Instituto Brasileiro de Geografia e Estatística. Disponível em: http://www. ibge.gov.br/home/default.php; Acesso em: dez. 2011.

BRASIL. MINISTÉRIO DA EDUCAÇÃO. Censo da Educação Superior 2010. Disponível em: http://portal.mec.gov.br/index.php?option=com_docman\&task=doc_ download\&gid=9332\&Itemid; Acesso em: jan. 2012.

BRASIL. MINISTÉRIO DA EDUCAÇÃO. Censo do Professor. Disponível em: http:// portal.mec.gov.br/index.php?option=comcontent\&view=article\&id=13596\&Item id=975; Acesso em: dez. 2011.

BRASIL. MINISTÉRIO DA EDUCAÇÃO. Instituto Nacional de Estudos e Pesquisas Educacionais Anísio Teixeira. Estudo exploratório sobre o professor brasileiro com base nos resultados do Censo Escolar da Educação Básica 2007. Brasília, 2009. Disponível em: http://portal.mec.gov.br/dmdocuments/estudoprofessor.pdf.

BUENO, Belmira Oliveira. Entre a antropologia e a história: uma perspectiva para a etnografia educacional. Perspectiva, Florianópolis: Ed. UFSC, v.25, p.471-501, 2007. Disponível em http://www.perspectiva.ufsc.br; Acesso em: jan. 2012.

COSTA, C. J. Modelos de educação superior a distância e implementação da Universidade Aberta do Brasil. Revista Brasileira de Informática na Educação, Campinas, SP, v.15, p.9-16, 2007.

COSTA, C. J.; DURAN, M. R. C. A Política Nacional de Formação de Professores entre 2005 e 2010: a nova Capes e o Sistema Universidade Aberta do Brasil. RBPG. Revista Brasileira de Pós-Graduação, v.9, n.16, p.263-313, abr. 2012, p.276-277.

COSTA, C. J.; DURAN, M. R. C.; AMIEL, T.; MASSARO, T. Relatório de pesquisa sobre avaliação de polos UAB. (Documento Interno). Niterói, RJ: Universidade Federal Fluminense, 2012.

COSTA, C. J.; DURAN, M. R. C.; MASSARO, T.; AMIEL, T. What are the presence support poles of Brazilian Open University system? In: EDULEARN 12: 4th International Conference on Education and New Learning Technologies, 2012, Barcelone, Spain. Proceedings... Madrid: International Association of Technology, Education and Development, 2012. v.1, p.60-75.

COSTA, C. J. (et al.) Região Norte, políticas de formação de professores e avaliação de polos do sistema Universidade Aberta do Brasil. Revista Eletrônica Gestão \& Saú- 
de, Brasília, v.1, p.1945-1957, 2013. Disponível em: http://www.gestaoesaude.unb. br/index.php/gestaoesaude/article/view/506; Acesso em: 30 maio 2014.

COSTA, C. J. (et al.) Um olhar da região Nordeste na avaliação dos polos do sistema Universidade Aberta do Brasil. Revista Eletrônica Gestão \& Saúde, v.1, p.13781407, dez. 2012. Disponível em: http://www.gestaoesaude.unb.br/index.php/gestaoesaude/article/view/396; Acesso em: 30 maio 2014.

DURAN, M. R. C.; COSTA, C. J.; AMIEL, T. The Open University System of Brazil: a study of learner support facilities in the North, Northeast and South Regions. Policy Futures in Education (Online), Oxford, v.12, p.221-228, 2014.

DURAN, M. R. C.; COSTA, C. J.; AMIEL, T.; EIDELWEIN, M. P. Netnography in the Universidade Aberta do Brasil System: research with coordinators from south, north and northeast centers. In: INTERNATIONAL TECHNOLOGY, EDUCATION AND DEVELOPMENT CONFERENCE, 7. Valencia, Spain, 2013. INTED2013 Proceedings, 2013. v.1, p.741-748.

KOZINETS, Robert. The Field Behind the Screen: Using Netnography For Marketing Research in Online Communities, 2002, p.2. Disponível em: http://www.nyu.edu/ classes/bkg/methods/netnography.pdf; Acesso em: 18 maio 2010.

MAMEDE-NEVES, Maria Apparecida Campos. Ensinando e aprendendo história. 5.ed. São Paulo: EPU, 2005.

MIRANDA, M. G.; RESENDE, A. C. A. Sobre a pesquisa-ação na educação e as armadilhas do praticismo. Revista Brasileira de Educação, São Paulo, v.11, p.511-518, 2006.

NOVOA, Antonio (Coord.) Vidas de professores. Porto: Ed. Porto, 1998.

SILVA, Edson Rosa Gomes da et al. Gestão de polo de apoio presencial no sistema Universidade Aberta do Brasil: construindo referenciais de qualidade. RENOTE - Revista Novas Tecnologias na Educação, v.8, n.3, dez. 2010. Disponível em: http://seer.ufrgs.br/renote/article/view/18086; Acesso em: 15 fev. 2011.

\section{NOTAS}

${ }^{1}$ ABED, 2013. Cabe observar que o Art. 80 da Lei no 9.394, de 20 de dezembro de 1996, a Lei de Diretrizes e Bases da Educação Nacional (LDB), regulamenta a modalidade a distância no Brasil. Nele se pode verificar que a modalidade depende de $30 \%$ de momentos presenciais, especialmente dedicados a avaliações. Assim, quando se trata de EAD para graduação no Brasil, se está sempre falando de uma modalidade semipresencial. Em tempo, conforme legislação vigente (Portaria $\mathrm{n}^{\circ} 4.059$, do Ministério da Educação, de 10 de dezembro de 2004), até $20 \%$ dos cursos presenciais podem ter disciplinas semipresenciais. 
Não obstante, disciplinas a distância/semipresenciais em cursos presenciais não tornam esse curso a distância ou semipresencial.

${ }^{2}$ COSTA; DURAN, 2012, p.276-277. Ver também COSTA, 2007.

${ }^{3}$ Ibidem, p.302.

${ }^{4}$ Desde junho de 2011 tem sido realizado um trabalho de pesquisa sobre o sistema Universidade Aberta do Brasil por um grupo de investigadores liderado por Maria Renata da Cruz Duran (UEL), Tel Amiel (Unicamp) e Celso Costa (UFF, coordenador geral). O trabalho conta com um cronograma de três fases: polos de apoio presencial, núcleos de educação a distância e recursos educacionais abertos. Entre 2011 e 2013, a primeira etapa foi realizada e teve como principal resultado uma tipologia dos polos de apoio presencial. Nessa etapa, 68 coordenadores de polos de apoio presencial estiveram em contato com o grupo de pesquisa "Formação de professores e novas tecnologias de informação e comunicação", vinculado ao Laboratório de Tecnologias Educacionais/UFF. Essa etapa teve como foco as regiões Norte, Nordeste e Sul. Nossas pesquisas foram realizadas a partir de entrevistas, nas quais a trajetória profissional dos entrevistados e o perfil de gestão dos polos teve destaque. Depois, por meio de visitas cruzadas, pares regionais foram estabelecidos e uma simulação de avaliação mútua foi executada. Conforme a participação de dois representantes de cada região, foram sistematizados e consolidados os dados auferidos nesta pesquisa. Todo o processo foi monitorado via Moodle e o que se apresenta no momento é uma síntese desse esforço colaborativo cujo objetivo era, primeiro, materializar um conhecimento sobre os polos $\mathrm{UAB}$ e, segundo, fomentar um debate mais amplo e aprofundado sobre as avaliações oficiais entre os coordenadores de polos UAB e os partícipes do sistema UAB como um todo. O ambiente Moodle usado nesta pesquisa ainda não foi aberto porque segue em uso nas etapas referentes ao estudo dos núcleos de educação a distância e da produção dos recursos educacionais abertos. Todavia, há vários substratos de nossas sondagens já publicados, bem como o relatório interno em que compilamos nossas fontes. Além dos trabalhos mencionados ao longo deste texto, podemos relacionar: COSTA; DURAN; MASSARO; AMIEL, 2012, e o recente AMIEL; DURAN; COSTA, 2014, ou ainda DURAN; COSTA; AMIEL, 2014. Em todas essas publicações, nosso leitor poderá dar-se conta da metodologia por nós adotada, bem como das contas colhidas - ainda que também possa estar certo de que dentro em pouco abriremos amplo acesso ao ambiente virtual Moodle que utilizamos para levantá-las.

${ }^{5}$ Ver também: COSTA (et al.), 2012, e COSTA (et al.), 2013.

${ }^{6}$ Disponíveis em http://portal.inep.gov.br/superior-censosuperior-sinopse.

${ }^{7}$ BRASIL. MINISTÉRIO DA EDUCAÇÃO, Censo da Educação Superior 2010. Ver também: http://portal.inep.gov.br/superior-censosuperior-sinopse.

${ }^{8}$ Informações fornecidas por e-mail, ao grupo de pesquisa, pela sra. Ismênia de Fátima Vieira, técnica da Diretoria do Ensino Superior da Secretaria Estadual de Educação de Santa Catarina, em 2012.

${ }^{9}$ Com a Lei Municipal no 3.884/2001, por exemplo, o município de Santo Antônio da Pa- 
trulha (RS) se responsabilizou por 50\% dos custos da formação inicial do professor. Outra ação do município que teve grande repercussão na formação dos professores foi o convênio entre as prefeituras de Santo Antônio da Patrulha e de Cará com a Universidade Federal do Rio Grande, em 2004, visando a formação em licenciatura em pedagogia para cem professores. Em 2006, com a implantação do Polo de Apoio Presencial da Universidade Aberta do Brasil, a formação continuada passou a ser o foco da política local. Em nossa pesquisa, outros 26 municípios estiveram em foco, contribuindo com informações sobre a formação de professores. Os resultados podem ser observados nas diversas publicações do grupo de pesquisa, bem como seu extrato final, ainda no prelo, previsto para publicação em novembro de 2014.

${ }^{10}$ BRASIL. MINISTÉRIO DA EDUCAÇÃO, 2009.

${ }^{11}$ BRASIL. MINISTÉRIO DA EDUCAÇAO. Censo do Professor.

${ }^{12}$ Segundo a Resolução CD/FNDE no 26, de 5 de junho de 2009, o coordenador de polo deve ser professor da rede pública, graduado e com, no mínimo, 3 anos em magistério na educação básica ou superior. Constatou-se que $91 \%$ dos coordenadores possui pelo menos 4 anos de experiência docente e pelo menos 2 anos de experiência administrativa. Ver http://www.capes.gov.br/educacao-a-distancia/atuab. Em toda a pesquisa contamos com a participação de 68 coordenadores de polos das regiões Norte, Nordeste e Sul, o que, em 2010 , representava $12 \%$ do universo de polos ativos do sistema. Todos eles foram selecionados de acordo com os seguintes critérios: integrantes do sistema UAB desde o primeiro ou o segundo edital (de cerca de quatro chamadas) de adesão, que passaram pelos dois processos avaliativos ocorridos até 2011 e nestes alcançaram, entre os cinco níveis de qualificação, notas consideradas medianas, melhor dizendo, aqueles que não obtiveram o nível máximo, nem foram desqualificados por falta de infraestrutura. Num primeiro momento, nosso projeto de pesquisa lhes foi apresentado para adesão ou não. Como passo seguinte, providências de sistematização da pesquisa foram implementadas e uma agenda de entrevistas foi estabelecida. Todas as 27 entrevistas com coordenadores da região Sul foram realizadas na mesma data, 17 de novembro de 2011, pelos três coordenadores da pesquisa: Celso José da Costa, Maria Renata da Cruz Duran e Tel Amiel.

${ }^{13}$ Quatro fóruns foram criados no ambiente Moodle para esse fim. O primeiro serviu para uma apresentação geral dos coordenadores, bem como para o registro de suas expectativas em relação à pesquisa. $\mathrm{O}$ segundo propunha uma discussão sobre os instrumentos de avaliação do MEC e da Capes, antes dos processos de visitas cruzadas. O terceiro propunha uma discussão sobre o preenchimento dos relatórios de visitas cruzadas e o modo como elas ocorreram - a ferramenta "envio de tarefas" foi utilizada para recebimento dos relatórios preenchidos. Um último fórum foi utilizado para levantar as opiniões dos participantes sobre os métodos de condução da pesquisa, bem como sobre o que se "ganhou" com ela. Todos esses fóruns, com duração de 15 a 20 dias de interação cada, foram tutorados por Maria Renata da Cruz Duran e Tatiana Massaro, que também se ocupou do mural de avisos e de um fórum específico sobre problemas e questões procedimentais da pesquisa. Destaque-se que cada uma das regiões foi atendida em separado. Os dados aqui auferidos 
dizem respeito apenas à região Sul; a análise dos dados das demais regiões pode ser consultada em DURAN; COSTA; AMIEL; EIDELWEIN, 2013.

${ }^{14}$ Ver http://www.capes.gov.br/educacao-a-distancia/atuab.

${ }^{15}$ Inicialmente cada instituição ofertante de curso fez a avaliação dos seus polos. Posteriormente, foi realizada avaliação pela Comissão Nacional de Qualificação de Polos da DED-Capes, com o objetivo de qualificar o polo e apontar melhorias. Em abril e maio de 2010, a SEED-MEC realizou nova avaliação a fim de atribuir nota aos polos, ao mesmo tempo em que impediu a expansão de alguns. O Inep também efetuou sondagens nesses polos, mas seu impacto foi minimizado, uma vez que os polos estavam resguardados pelo processo de credenciamento experimental.

${ }^{16}$ Participaram da pesquisa os coordenadores de polos dos municípios discriminados a seguir. Do Paraná: Foz do Iguaçu, Astorga, Ibaiti, Jacarezinho, Diamante do Norte, Paranaguá, Itambé, Pato Branco, Cruzeiro do Oeste e Engenheiro Beltrão. De Santa Catarina: Braço do Norte, Indaial, São Miguel do Oeste, Chapecó, Araranguá, Laguna e Criciúma. Do Rio Grande do Sul: Sobradinho, Novo Hamburgo, Santo Antônio da Patrulha, Santa Vitória do Palmar e Quaraí.

${ }^{17}$ Segundo KOZINETS (2002, p.2), a netnografia é uma nova metodologia de pesquisa qualitativa que se adapta às técnicas de pesquisa etnográficas para o estudo das culturas e das comunidades emergentes através da comunicação mediada por computador. Ver também DURAN; COSTA; AMIEL; EIDELWEIN, 2013.

${ }^{18}$ A coordenadora do polo de Quaraí (RS) relatou um exemplo no qual os alunos do curso de física foram à universidade, avaliando o resultado da experiência como excelente. Para ela, as aulas de laboratórios podem ser ofertadas nas IES, pois "a ida dos alunos até a universidade desperta a curiosidade e eleva a autoestima dos acadêmicos, pois conhecem a instituição a que estão vinculados, oportunizando a vivência com alunos do presencial" (Coordenadora de Quaraí/RS, 2012. In: COSTA; DURAN; AMIEL; MASSARO, 2012).

Artigo recebido em 30 de maio de 2014. Aprovado em 27 de junho de 2014. 